\title{
O Indicador Anos Potenciais de Vida Perdidos e a Ordenação das Causas de Morte em Santa Catarina, 1995*
}

\author{
Heloisa Côrtes Gallotti Peixoto \\ Universidade Federal de Santa Catarina \\ Maria de Lourdes de Souza \\ Universidade Federal de Santa Catarina
}

\begin{abstract}
Resumo
O indicador Anos Potenciais de Vida Perdidos (APVP) em menores de 70 anos é apresentado como alternativa ao critério tradicionalmente utilizado para a ordenação das principais causas de mortalidade. Utilizando a base de dados de mortalidade para Santa Catarina, em 1995, são analisadas as alterações ocorridas na ordenação e na importância relativa das causas de óbito, considerando o critério proposto. No ano estudado, foram tolhidos, no total, 440.939 anos potenciais de vida, que representou, em média, 28,1 anos para cada óbito. A utilização do indicador na ordenação das causas de óbito aumentou a importância relativa das causas externas e das que têm maior incidência em crianças, como as perinatais, anomalias congênitas $e$ as infecções intestinais. Em ordem de importância de APVP, as principais causas de mortalidade foram os acidentes de trânsito (15,5\%), as afecções originadas no período perinatal (14,6\%) e os outros acidentes (9,3\%). A lógica de valorização da mortalidade prematura, implícita no indicador, assim como a simplicidade de cálculo e interpretação, parecem apontar para a sua crescente incorporação no processo de planejamento e avaliação em saúde.
\end{abstract}

\section{Palavras-Chave}

Anos Potenciais de Vida Perdidos; Mortalidade; Indicadores de Saúde.

\section{Summary}

Potential Years of Life Lost (PYLL), for persons under the age of 70, is presented as an alternative indicator to the traditionally employed one in listing the main causes of mortality. The article analyzes changes in the listing and in the relative importance of death causes considering the new proposed indicator, using mortality data-base from Santa catarina State in 1995. Throughout that year, 440.939 potential years of life were cut short, representing an average of 28.1 years per death. The use of the indicator in listing the causes increased the relative importance of external causes, and those having greater importance upon children, such as perinatal deaths, congenital abnormalities, and intestinal infections. Using PYLL the order of importance of the main causes of mortality were the transit accidents (15.5\%), affections originated during the perinatal phase (14.6\%), and the other accidents (9.3\%). The rationale of valuing premature mortality, implicit in the indicator, as well as the simplicity of its figuring out and interpretation, seems to point towards its growing incorporation to the health planning process and evaluation.

\section{Key Words}

Potential Years of Life Lost; Mortality; Health Indicators.

\footnotetext{
* Artigo originado da dissertação de mestrado "Mortalidade em Santa Catarina. Aplicações do Indicador Anos Potenciais de Vida Perdidos".

Endereço para correspondência: Rua 23 de Março, 312 - Itaguaçú - Florianópolis - Santa Catarina - CEP: 88085-440

E-mail: helo@saude.sc.gov.br
} 


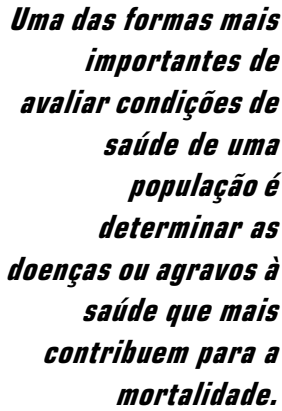
mortalidade.

\section{Introdução}

Uma das formas mais importantes de avaliar condições de saúde de uma população é determinar as doenças ou agravos à saúde que mais contribuem para a mortalidade, isto é, a classificação ou o ordenamento das suas principais causas de morte. A questão central envolvida neste artigo refere-se à utilidade da aplicação do indicador Anos Potenciais de Vida Perdidos - APVP, na comparação da importância relativa dessas causas.

Tradicionalmente, na ordenação das causas de óbito, a posição ocupada por determinada causa está relacionada com a quantidade de óbitos que ela provocou, atribuindo-se o mesmo peso a qualquer causa, independente da idade em que ocorreram as mortes. Quando se ordenam as causas de óbitos dessa forma, o critério utilizado é, portanto, a magnitude das causas.

No entanto, quando o objetivo é selecionar prioridades, devem-se considerar outros aspectos, como a vulnerabilidade do dano, isto é, a capacidade operacional de reduzir o dano e sua transcendência, entendida como o valor social atribuído ao problema. O ideal é considerar uma combinação de critérios.

Foi partindo desse pressuposto que se originou a idéia de que o tempo de vida perdido por morte em cada idade deveria ser um critério importante para estabelecer o ranking das principais causas de mortalidade e comparar sua importância relativa.

Segundo Werneck e Reichenheim, ${ }^{1}$ o indicador APVP, explicitando o total de anos potenciais de vida perdidos para cada óbito, "qualifica" as mortes e introduz um novo critério para a seleção de prioridades.

A utilização do APVP propõe um reordenamento das causas de óbito, considerando o momento em que as mortes ocorreram. Estabelece pesos diferentes para cada causa, de acordo com o número de anos potenciais de vida que elas tolheram de suas vítimas. A mortalidade prematura é entendida aqui como a expressão do valor social da morte, pois, quando a morte ocorre numa etapa em que a vida é potencialmente produtiva, não afeta somente o indivíduo e o grupo que convive diretamente com ele, mas a coletividade como um todo, que é privada do seu potencial econômico, intelectual e do vir a ser do sujeito na sociedade.

$\mathrm{O}$ indicador incorpora ainda o critério da vulnerabilidade, visto que os óbitos ocorridos em idades menos avançadas são mais fáceis de serem evitados.

Várias pesquisas ${ }^{2,3,4,5}$ têm demonstrado a importância do uso desse indicador que apresenta, ainda, como ponto positivo, a facilidade de cálculo e a possibilidade de ser, desde que conhecido, amplamente utilizado.

O objetivo deste artigo foi determinar e analisar os APVP para as principais causas de óbito de Santa Catarina, em 1995, ressaltando a importância da utilização do indicador como instrumento de orientação no estabelecimento de prioridades. Resgata-se, desse modo, a função primordial das estatísticas de mortalidade, que podem e devem nortear a tomada de decisões na área da saúde.

\section{Metodologia}

A base de dados utilizada refere-se aos óbitos de residentes no Estado de Santa Catarina, ocorridos durante o ano de 1995 e processados pelo Sistema de Informações sobre Mortalidade - SIM.

Para descrição e análise das causas de morte, foi utilizada a Classificação Internacional de Doenças, na sua Nona Revisão. ${ }^{6}$ As causas de óbito foram agrupadas segundo a lista CID-BR2, que permite uma agregação mais voltada para a capacidade de atuação, fornecendo melhor compreensão do perfil da mortalidade e das possibilidades de intervenção. Em algumas situações, como no caso da mortalidade por causas externas, recorreu-se à análise detalhada de um grupo de causas, com o objetivo de verificar os principais diagnósticos incluídos no grupo.

Neste artigo, o método do cálculo de APVP por uma determinada causa foi obtido por uma adaptação da proposta por 
Romeder e McWhinnie, ${ }^{7}$ cuja expressão matemática é dada como:

\section{Limite superior}

$$
\begin{gathered}
\text { Apvp }=\Sigma \text { aidi onde: } \\
\mathbf{i}=\text { limite inferior }
\end{gathered}
$$

ai $=$ número de anos que faltam para completar a idade correspondente ao limite superior considerado, quando a morte ocorre entre as idades de i e i +1 anos;

di $=$ número de óbitos ocorridos entre as idades de i e i +1 anos.

Apesar de a maioria dos autores utilizarem esse método, existe muitas divergências em relação à escolha do limite potencial de vida. ${ }^{8}$ Neste trabalho, consideraram-se todos os óbitos, ocorridos até os 69 anos.

Com o objetivo de demonstrar, passo a passo, os procedimentos de cálculo do número de APVP para uma causa específica, apresenta-se a Tabela 1 , construída a partir da distribuição de óbitos por AIDS, ocorridos em Santa Catarina, em 1995, segundo faixas etárias. Para distorcer o menos possível a distribuição dos óbitos por faixas etárias, é aconselhável a utilização de intervalos com amplitude menor (cinco anos) do que a apresentada no exemplo.

O somatório da coluna 4 (13.415) representa o total de APVP por AIDS, que pode ser dividido pelo total de óbitos pela mesma causa (372), a fim de obterse o número médio de APVP para cada óbito por AIDS. Este resultado permitiria dizer que cada óbito por AIDS "roubou", em média, 36,1 anos potenciais de vida, ocorrendo, em média, aos 33,9 anos (70$36,1)$.

Utilizando a planilha do "Excel", os grupos de causas foram ordenados, segundo o número de APVP. Foram ainda calculados percentuais de APVP de cada grupo, em relação ao total de APVP, excluídos desse total os APVP por "causas mal definidas", por ser categoria não discriminativa.

A mesma ordenação e o cálculo das proporções foram feitos sem a utilização do critério do APVP, a fim de demonstrar as alterações ocorridas no ordenamento e na importância relativa das causas.

A média de APVP por óbito, para cada grupo de causas, foi calculada na planilha, como resultado da divisão do total de APVP pelo número de óbitos considerados. Esse procedimento permite conhecer ainda, a idade média em que ocorreram os óbitos, também incluída nas tabelas de apresentação dos dados, pela diminuição desse valor do limite superior adotado.

\begin{tabular}{|c|c|c|c|c|}
\hline \multirow{2}{*}{$\begin{array}{l}\text { Faixas } \\
\text { Etárias }\end{array}$} & $\begin{array}{l}\text { Número de } \\
\text { Óbitos } \\
\text { (1) }\end{array}$ & $\begin{array}{c}\text { Ponto Médio } \\
\text { do Intervalo } \\
(2)\end{array}$ & $\begin{array}{c}\text { Anos Potenciais de } \\
\text { Vida no Intervalo } \\
(3)\end{array}$ & $\begin{array}{c}\text { Anos Potenciais } \\
\text { de Vida Perdidos } \\
\text { no Intervalo } \\
(4)\end{array}$ \\
\hline & $\begin{array}{c}\text { Fonte: Sistema de } \\
\text { Informações sobre } \\
\text { Mortalidade }\end{array}$ & $\begin{array}{l}\text { Semi-soma dos } \\
\text { limites inferiores } \\
\text { de duas classes } \\
\text { subseqüentes }\end{array}$ & $\begin{array}{c}\text { Diferença entre o } \\
\text { limite superior } \\
\text { considerado e o } \\
\text { ponto médio do } \\
\text { intervalo } \\
\end{array}$ & $\begin{array}{l}\text { Produto da coluna } \\
3 \text { pela coluna } 1\end{array}$ \\
\hline 0 a 1 ano & 7 & 0,5 & 69,5 & 486,5 \\
\hline 1 a 4 & 8 & 3,0 & 67,0 & 536,0 \\
\hline 5 a 9 & 0 & 7,5 & 62,5 & 0,0 \\
\hline 10 a 14 & 0 & 12,5 & 57,5 & 0,0 \\
\hline 15 a 19 & 1 & 17,5 & 52,5 & 52,5 \\
\hline 20 a 29 & 108 & 25,0 & 45,0 & $4.860,0$ \\
\hline 30 a 39 & 159 & 35,0 & 35,0 & $5.565,0$ \\
\hline 40 a 49 & 64 & 45,0 & 25,0 & $1.600,0$ \\
\hline 50 a 59 & 19 & 55,0 & 15,0 & 285,0 \\
\hline 60 a 69 & 6 & 65,0 & 5,0 & 30,0 \\
\hline Total & 372 & & & $13.415,0$ \\
\hline
\end{tabular}

Tabela 1 - Óbitos e APVP por AIDS, Santa Catarina, 1995

\section{Resultados e Discussão}

A Tabela 2 resume os resultados encontrados neste trabalho. Os grupos de causas, agregados segundo a lista CIDBR2, estão ordenados pelo critério de Anos Potenciais de Vida Perdidos. Observam-se alterações importantes, tanto na posição hierárquica ocupada pelas causas, como no percentual em relação ao total.

As três primeiras colunas apresentam, para cada grupo de causas, para o total das causas definidas, para o 
Tabela 2 - APVP e óbitos (de 0 a 70 anos), segundo grupos de causas, Santa Catarina, 1995

\begin{tabular}{|c|c|c|c|c|c|c|c|c|}
\hline \multirow{2}{*}{\multicolumn{2}{|c|}{$\begin{array}{ll} & \text { APVP } \\
\text { Posição } & \text { Grupos de Causas (Cid-Br2) }\end{array}$}} & \multirow{2}{*}{\multicolumn{3}{|c|}{ APVP }} & \multicolumn{4}{|c|}{ Óbitos } \\
\hline & & & & & \multirow{2}{*}{$\begin{array}{c}\text { Número } \\
1.574\end{array}$} & \multirow{2}{*}{$\begin{array}{c}\begin{array}{c}\text { Idade } \\
\text { Média }\end{array} \\
30,8\end{array}$} & \multirow{2}{*}{$\begin{array}{c}\text { Posição } \\
2\end{array}$} & \multirow{2}{*}{$\%$} \\
\hline 1 & Acidentes de trânsito de veículo a motor & $\begin{array}{l}\text { Número } \\
61.652,0\end{array}$ & $\%$ & $\frac{\text { APVP/Óbito }}{39,2}$ & & & & \\
\hline 2 & Afec. orig. período perinatal & $58.095,5$ & 14,6 & 69,5 & 836 & 0,5 & 6 & 6,1 \\
\hline 3 & Acidentes (exceto de trânsito) & $36.944,0$ & 9,3 & 42,6 & 867 & 27,4 & 5 & 6,3 \\
\hline 4 & Neoplasmas malignos & $36.794,5$ & 9,3 & 16,4 & 2.245 & 53,6 & 1 & 16,3 \\
\hline 5 & Anomalias congênitas & $20.605,0$ & 5,2 & 66,3 & 311 & 3,7 & 13 & 2,3 \\
\hline 6 & Infecções respiratórias agudas & $18.642,0$ & 4,7 & 42,4 & 440 & 27,6 & 9 & 3,2 \\
\hline 7 & Doença cerebrovascular & $17.127,5$ & 4,3 & 14,1 & 1.211 & 55,9 & 3 & 8,8 \\
\hline 8 & Doença isquêmica do coração & $15.091,0$ & 3,8 & 12,9 & 1.171 & 57,1 & 4 & 8,5 \\
\hline 9 & Homicídios & $14.770,0$ & 3,7 & 37,8 & 391 & 32,2 & 10 & 2,8 \\
\hline 10 & D. da circ. pulmonar e outras do coração & $10.960,5$ & 2,8 & 16,6 & 662 & 53,4 & 7 & 4,8 \\
\hline 11 & Suicídios & $10.375,0$ & 2,6 & 31,3 & 331 & 38,7 & 12 & 2,4 \\
\hline 12 & Doenças infecciosas intestinais & $8.010,5$ & 2,0 & 55,2 & 145 & 14,8 & 17 & 1,1 \\
\hline 13 & Doença crônica do fígado e cirrose & $7.298,0$ & 1,8 & 20,9 & 349 & 49,1 & 11 & 2,5 \\
\hline 14 & Doen. pulm. obstrut. crônica e afec. afins & $6.605,5$ & 1,7 & 11,9 & 556 & 58,1 & 8 & 4,0 \\
\hline 15 & Meningites & $6.199,0$ & 1,6 & 56,9 & 109 & 13,1 & 20 & 0,8 \\
\hline 16 & Septicemia & $4.770,0$ & 1,2 & 40,1 & 119 & 29,9 & 19 & 0,9 \\
\hline 17 & Diabetes mellitus & $3.888,0$ & 1,0 & 12,7 & 307 & 57,3 & 14 & 2,2 \\
\hline 18 & Doenças do aparelho urinário & $3.159,0$ & 0,8 & 21,1 & 150 & 48,9 & 16 & 1,1 \\
\hline 19 & Edema agudo e outras doenças do pulmão & $3.012,0$ & 0,8 & 28,4 & 106 & 41,6 & 21 & 0,8 \\
\hline 20 & Lesões em que se ignora se foram acid. ou intenc & $2.918,0$ & 0,7 & 34,3 & 85 & 35,5 & 23 & 0,6 \\
\hline 21 & Transtornos mentais & $2.415,0$ & 0,6 & 29,5 & 82 & 40,5 & 25 & 0,6 \\
\hline 22 & Apend hern cav abdom e out afec intest e perin & $2.340,0$ & 0,6 & 18,9 & 124 & 51,1 & 18 & 0,9 \\
\hline 23 & Neoplasias benignas & $2.335,0$ & 0,6 & 24,8 & 94 & 45,2 & 22 & 0,7 \\
\hline 24 & Doença hipertensiva & $2.295,0$ & 0,6 & 14,3 & 161 & 55,7 & 15 & 1,2 \\
\hline 25 & Doen infec redut saneam contr vetor e out med & $1.834,0$ & 0,5 & 32,8 & 56 & 37,3 & 28 & 0,4 \\
\hline 26 & Deficiências nutricionais e anemias carenciais & $1.684,5$ & 0,4 & 48,1 & 35 & 21,9 & 30 & 0,3 \\
\hline 27 & Epilepsia & $1.534,5$ & 0,4 & 38,4 & 40 & 31,6 & 29 & 0,3 \\
\hline 28 & $\mathrm{D}$ infec redutíveis $\mathrm{p}$ diag e tratam precoce & $1.449,5$ & 0,4 & 24,2 & 60 & 45,8 & 27 & 0,4 \\
\hline 29 & Doenças do esôfago, estômago e duodeno & $1.333,5$ & 0,3 & 20,8 & 64 & 49,2 & 26 & 0,5 \\
\hline 30 & Doenças das artérias arteríolas e capilares & $1.209,0$ & 0,3 & 14,2 & 85 & 55,8 & 24 & 0,6 \\
\hline \multirow[t]{5}{*}{31} & Complicações da gravidez, do parto e puerpério & $1.112,0$ & 0,3 & 41,2 & 27 & 28,8 & 32 & 0,2 \\
\hline & Todas as outras doenças e lesões (definidas) & 30.772 & 7,7 & 31,1 & 988 & 38,9 & & 7,2 \\
\hline & Subtotal & $397.231,0$ & 100,0 & 28,8 & 13.781 & 41,2 & & 100,0 \\
\hline & Sinais, sintomas e afecções mal-definidas & $43.708,0$ & 9,9 & 23,1 & 1.892 & 46,9 & & 12,1 \\
\hline & TOTAL & $440.939,0$ & & 28,1 & 15.673 & 41,9 & & \\
\hline
\end{tabular}

grupo das causas mal definidas e para o total geral, os seguintes valores: coluna 1: número de APVP; coluna 2: proporção em relação ao total de APVP por causas definidas; coluna 3: média de APVP por óbito (obtida pela divisão do número de APVP pelo número de óbitos). As outras colunas foram incluídas na tabela com o objetivo de permitir a comparação, do ordenamento e da importância relativa dos grupos de causas, obtido a partir do indicador proposto, com o que resultaria se considerássemos somente a freqüência de óbitos em cada grupo.

Juntas, as 15 principais causas de APVP, representam 82,9 \% do total de anos potenciais de vida perdidos, por causas definidas, em Santa Catarina, no ano de 1995.

A Figura 1 agrupa alguns dos principais grupos de causas, mostrando a participação percentual de cada grupo, usando o número bruto de mortes, bem como os anos potenciais de vida.

As doenças do aparelho circulatório, que representavam um quarto do total de óbitos, diminuem a sua importância relativa $(12,8 \%)$ quando o critério é o número de APVP tolhidos. $\mathrm{O}$ mesmo acontece com o grupo das neoplasias malignas, que tem sua participação quase que reduzida à metade, em função da maioria dos óbitos ocorrerem em idades avançadas.

Já as causas violentas (acidentes, homicídios e suicídios), têm freqüência que resulta em uma proporção maior de APVP $(31,8 \%)$ do que do total de óbitos $(23,5 \%)$ porque, freqüentemente, suas vítimas são crianças e jovens.

As mortes por afecções perinatais e anomalias congênitas, embora relativamente pequenas em número, respondem por uma considerável proporção do total de APVP, $14,6 \%$ e $5,2 \%$ respectivamente, passando a 
ocupar lugar de destaque.

Também observam-se alterações na importância relativa dos grupos que incluem as infecções respiratórias agudas e as infecciosas intestinais, que assumem maior importância quando a ordenação usa o critério dos APVP.

A explicação para essas alterações pode ser encontrada na coluna da Tabela 2, que apresenta os APVP por óbito, que mostra, por exemplo, porque causas como as peri-natais, as anomalias congênitas, meningites e infecciosas intestinais, "roubando", em média, mais de 50 anos potenciais de vida de cada vítima, subiram no

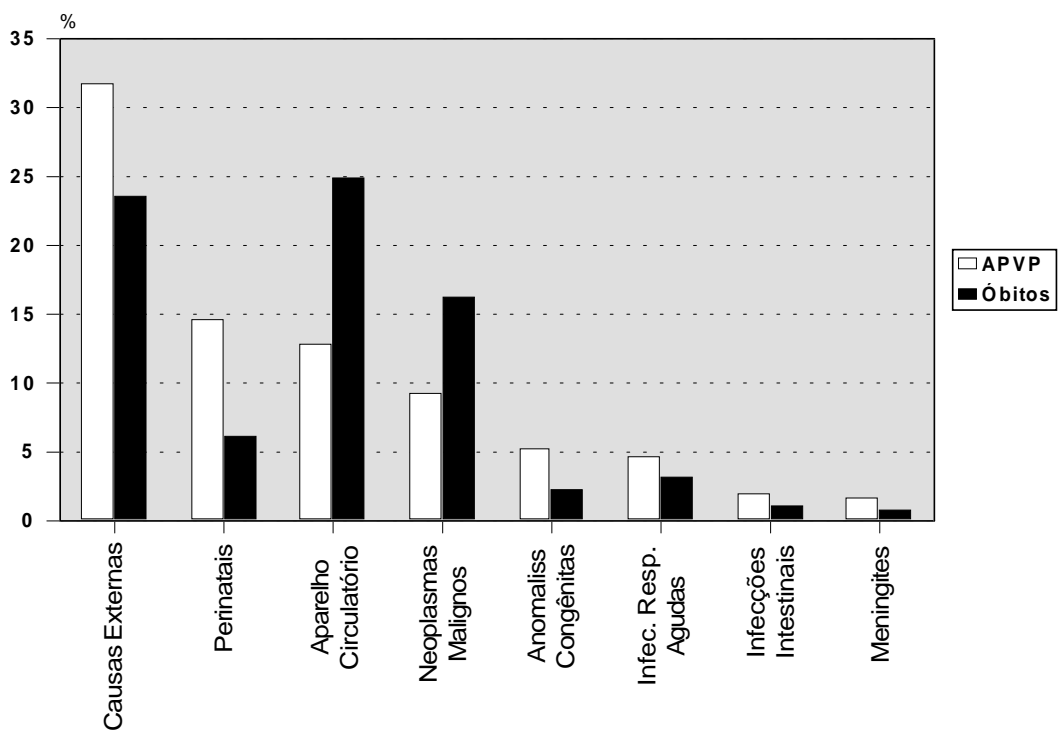

Figura 1 - Percentual de APVP e óbitos, segundo alguns grupos de causas, Santa Catarina, 1995

ordenamen-to, quando o critério utilizado foi o APVP.

Já as doenças crônicodegenerativas, com uma média de APVP por óbito muito mais baixa, caem na ordenação, perdendo grande parte da sua importância relativa.

Os "acidentes de trânsito de veículo a motor", que já ocupavam o $2^{\circ}$ lugar quando o critério era o número de óbitos, tolheram o maior número de APVP (61.652), passando a ocupar a $1^{\mathrm{a}}$ posição entre as causas de óbito. $\mathrm{O}$ peso relativo desta causa, que anteriormente era de $11,4 \%$ dos óbitos, teve seu valor bastante aumentado, correspondendo agora a $15,5 \%$ do total de APVP. Essa causa "roubou" 39,2 anos de cada vítima, o que equivale dizer que os óbitos por acidentes de trânsito ocorreram, em média, aos 31,9 anos. Em Santa Catarina, segundo estimativas baseadas nos dados processados pela Gerência de Estatística e Informática da Secretaria de Estado da Saúde, o risco de morrer por acidentes de trânsito era de 20,8 para cada 100.000 habitantes, em 1980, passando a 33,9 em 1995 , o que representa um aumento acumulado no período de $63 \%$. Aproximadamente, um quarto desses óbitos é de "acidentes envolvendo pedestre", isto é, atropelamentos, dos quais $22 \%$, atingem menores de 15 anos.

$\mathrm{Na}$ verdade, todos os subgrupos incluídos no capítulo das "Causas
Externas" subiram de posição com a utilização do critério APVP. Os "Outros acidentes", passaram de $5^{\circ}$ para o $3^{\circ}$ lugar, os "homicídios", do $10^{\circ}$ para o $9^{\circ}$, e os suicídios, da $12^{\mathrm{a}}$ para a $11^{\mathrm{a}}$ posição. Como resultado da própria natureza de não escolher a idade entre suas vítimas, a importância relativa das causas externas tendem a aumentar quando considerado o critério dos APVP.

À medida que se faz mais eficaz a luta contra as enfermidades, as mortes violentas, principalmente os acidentes, adquirem uma importância proporcional cada vez maior, chegando a ser a principal causa de morte entre crianças e adolescentes, mesmo quando não se utiliza o critério APVP. Em determinados grupos de idade, o número de mortes por acidentes é superior ao de todas as demais causas de morte reunidas.

Esse aumento dos acidentes também está relacionado ao contexto do progresso técnológico, como o desenvolvimento da eletrificação e o emprego de inseticidas e agrotóxicos e a análise detalhada dos tipos de acidentes mais freqüentes, assim como dos principais grupos atingidos, é fundamental para nortear as medidas preventivas.

$\mathrm{O}$ preenchimento incorreto da declaração de óbito por parte dos legistas, não permite, muitas vezes identificar, de 
À medida que se faz mais eficaz a luta contra as enfermidades, as mortes violentas, principalmente os acidentes, adquirem uma importância proporcional cada vez maior, chegando a ser a principal causa de morte entre crianças e adolescentes, mesmo quando não se utiliza o critério APVP. forma apropriada, a circunstância do acidente ou da violência que produziu a lesão fatal. É o caso dos atestados que informam, por exemplo, "politraumatismo" ou "traumatismo crânio encefálico", para os quais a Classificação Internacional de Doenças determina que sejam codificados, numa categoria residual, como "acidente não especificado". Em Santa Catarina, no ano de 1995, quase um quarto dos 951 óbitos ocorridos por acidentes, excluídos os de trânsito, foi incluído nesta categoria residual, mas é possível, ainda assim, analisar as principais causas de acidentes, com base nos dados disponíveis.

Quase $30 \%$, ou seja, 285 óbitos, foram devido a "afogamentos", dos quais $23 \%$ ocorreram na faixa etária de menores de 15 anos.

Em segundo lugar, aparecem as "quedas acidentais", responsáveis por 132 óbitos, com concentração significativa em maiores de 50 anos, que respondem por 52,3\% dos óbitos por essa causa.

Os óbitos devido a "obstrução do trato respiratório por alimento ou objeto", também aparecem em posição de destaque, e muito contribuem para os APVP contabilizados, visto que, quase a totalidade dos 102 óbitos por esta causa $(82 \%)$ ocorreram na faixa etária de menores de cinco anos.

Já os "acidentes causados por corrente elétrica", concentram-se na faixa de idade mais produtiva, de 15 a 49 anos, responsável por $78 \%$ dos óbitos neste subgrupo.

Apesar de aparecerem com uma freqüência menor, a constatação de que um terço dos óbitos por "acidentes envolvendo fogo e chama", vitimou crianças e adolescentes de até 15 anos, mostra a importância de medidas preventivas para esse tipo de acidentes.

É preciso salientar que esses acidentes não são unicamente importantes como causa de morte. Estima-se que o número de acidentes não mortais seja 100 a 200 vezes maior que o de mortes, o que pode dar uma idéia sobre os sofrimentos e a perda que os acidentes deixam atrás de si.

Da mesma forma que para as enfermidades, a frequiência dos acidentes ocorridos em uma população implica certas relações importantes, mas, mal compreendidas até agora, entre o sujeito exposto, o agente e o meio. $\mathrm{O}$ método epidemiológico permite enfocar, de um modo científico, o estudo dos acidentes e das medidas preventivas, tendo as estatísticas de mortalidade a função de indicar quais os tipos de acidentes que exigem uma investigação epidemiológica detalhada.

A Classificação Internacional de Doenças proporciona informações sobre o tipo e condições do acidente, mas, não fornece uma idéia detalhada de seus diversos aspectos, que exigem investigação epidemiológica. Vimos, por exemplo, que os afogamentos, são importante causa de mortalidade, mas, é o estudo dos fatores que originam ou que contribuem para os casos de morte por afogamento (banhos em lugares perigosos, incapacidade de nadar, ignorância dos métodos de salvamento, falta de assistência ou de meios adequados para reanimar os que estão se afogando) que revelará a importância de determinadas circunstâncias, orientando as medidas que devem ser aplicadas para reduzir esses acidentes.

O grupo das "meningites" ascendeu cinco posições na escala hierárquica, tirando quase 57 anos potenciais de vida de cada vítima. Quando a ordenação é feita com base no número de óbitos, as meningites aparecem como a $20^{\mathrm{a}}$ causa, passando para $15^{\mathrm{a}}$ posição em relação ao número de APVP.

As "infecções respiratórias agudas" e as "doenças infecciosas intestinais" também subiram cinco posições (as primeiras, da $12^{\mathrm{a}}$ para a $7^{\mathrm{a}} \mathrm{e}$ as segundas, da $17^{\mathrm{a}}$ para a $12^{\mathrm{a}}$ ). Estes grupos, apesar de terem "roubado" menos APVP por óbito do que as meningites, têm uma importância relativa maior, em função do número de óbitos ocorridos. No total, enquanto as meningites tolheram 6.199 APVP, as infecciosas intestinais foram responsáveis por mais de 8.000 APVP e as infecções respiratórias agudas, 10.583 .

As "septicemias" e as "deficiências nutricionais e anemias carenciais", por incidirem em idades mais jovens, também 
sobem na ordenação, aumentando sua importância relativa em relação ao total de APVP.

Aparecendo em lugar de destaque

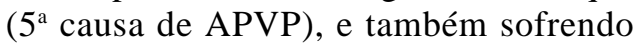
grande alteração com a utilização do critério de APVP (oito posições), as "anomalias congênitas", mais que dobraram a sua importância relativa. A explicação para essa alteração tão expressiva é encontrada na coluna dos APVP por óbito. Foram as "afecções originadas no período perinatal" e as "anomalias congênitas" os grupos que mais tiraram anos potenciais de vida de cada uma das pessoas que morreram $(69,5$ e 66,3 anos, respectivamente).

Em relação a esses dois grupos, no entanto, é preciso lembrar que, se o procedimento de excluir a mortalidade neonatal precoce fosse adotado, a sua importância relativa diminuiria sensivelmente, visto que aproximadamente $40 \%$ das anomalias congênitas e $80 \%$ das afecções originadas no período perinatal ocorreram antes de completados os sete dias de vida. Mesmo concordando que boa parte desses óbitos são difíceis de serem evitados, a posição de destaque ocupada por esses grupos, principalmente o das perinatais, que se colocam como a $2^{\text {a }}$ causa de APVP, aponta a necessidade de investir mais no pré-natal e assistência ao parto.

Apesar de aparecer em $21^{\circ}$ lugar na ordenação dos APVP e não ter alterado sua participação percentual, é interessante observar o comportamento do grupo dos "transtornos mentais", que subiu quatro posições, também pelo fato de incidirem numa faixa de idade jovem (75,6\% dos óbitos ocorreram entre 15 e 19 anos). As duas primeiras causas desse grupo foram a "síndrome da dependência do álcool" e a "dependência de drogas", que inclui as mortes por overdose de cocaína e outras drogas. Juntas, essas causas foram responsáveis por $87,23 \%$ do total de óbitos incluídos no grupo.

Por outro lado, alguns grupos perdem grande parte da sua importância relativa sob a ótica dos APVP. As "doenças cerebro-vasculares", as "doenças isquêmicas do coração", e as "doenças da circulação pulmonar e outras formas de doença do coração", que ocupavam a $3^{\text {a }}$, $4^{\mathrm{a}}$ e $7^{\mathrm{a}}$ colocação entre as causas de óbito, caíram para $7^{\text {a }}, 8^{\text {a }}$ e $10^{\text {a }}$ posição, respectivamente. Isso acontece porque esses óbitos ocorrem, em média, após os 55 anos, quando o número de anos que se esperaria viver, se considerado o limite de idade de 70 anos, gira em torno de 15 .

Ainda dentro das doenças do aparelho circulatório, o grupo das "doenças hipertensivas" mostra a maior alteração em termos de queda na classificação, fazendo com que o grupo passe a se colocar nove posições abaixo da ocupada antes da aplicação do indicador APVP.

Nota-se que o grupo dos "neoplasmas malignos", que ocupava o $1^{\circ}$ lugar, com $16,3 \%$ do total de óbitos, mesmo com o critério do APVP se mantém em posição de destaque, aparecendo como $4^{\mathrm{a}}$ causa. Esse grupo, não sofreu uma queda acentuada na escala hierárquica como a observada entre as doenças do aparelho circulatório, porque estas últimas ocorrem em idades mais avançadas.

Para alguns grupos, o mais importante não é verificar as alterações ocorridas com o uso do critério proposto, mas, utilizar o indicador para demonstrar sua importância, em termos de prioridade, e até para sensibilizar os responsáveis pela tomada de decisões no setor saúde. Esse é o caso, por exemplo, das "complicações da gravidez, parto e puerpério”. No ano estudado, foram registrados 27 óbitos por causas maternas. Se comparamos esse número com os 2.245 óbitos ocorridos por Neoplasias, ou os 1.574 por acidentes de trânsito, ele acaba parecendo tão pequeno que não justificaria incluí-lo entre as prioridades. A informação de que esse grupo "roubou" 1.112 anos de vida potencial das suas vítimas pode ser muito mais convincente quando aliada aos demais componentes de sua interpretação. Aqui, é importante lembrar que as mortes maternas são geralmente subnotificadas, em função do preeenchimento incorreto da declaração de óbito. Pesquisas têm demonstrado ser necessário usar um fator de correção para obter um número de óbitos por causas maternas mais próximo do real. Alguns autores ${ }^{9,10}$ propõem um 
Oemprego do indicador APVP na análise da ordenação das causas de óbito demonstrou a sua distinção em relação aos indicadores tradicionalmente utilizados, lembrando que não são antagônicos, mas, complementares. fator de correção da ordem de 2,04, para a Região Sul, o que mais que dobraria o número de APVP desse grupo. Além disso, $98 \%$ das mortes maternas são reconhecidamente evitáveis e ocorrem numa faixa de idade produtiva.

$\mathrm{O}$ mesmo raciocínio anterior pode ser aplicado ao grupo das "doenças imunopreveníveis". Apesar de terem ocorrido, em 1995, somente 16 óbitos por estas causas, estes tolheram 442 anos potenciais de vida perdidos, enfatizando a necessidade de manter altas coberturas vacinais.

Finalmente, é importante ressaltar que, se incluído no ordenamento, o grupo das "mal definidas" ocuparia o $2^{\circ}$ lugar entre as causas de óbito e a $3^{\text {a }}$ posição entre os APVP. Se essas causas pudessem ser definidas, o padrão de mortalidade poderia alterar-se consideravelmente.

\section{Considerações Finais}

O emprego do indicador APVP na análise da ordenação das causas de óbito demonstrou a sua distinção em relação aos indicadores tradicionalmente utilizados, lembrando que não são antagônicos, mas, complementares. As alterações observadas na ordenação das causas de morte, com a utilização do critério APVP, demonstram a validade do indicador, pela ênfase dada à mortalidade prematura.

As cinco principais causas de óbito, ordenadas segundo o indicador aplicado, representam mais da metade $(53,9 \%)$ de todos os APVP por causas definidas. Se considerarmos as dez principais causas de APVP, a proporção chega a 73,2\%.

A constatação de que 61.652 anos potenciais de vida dos residentes em Santa Catarina estão sendo perdidos em acidentes de trânsito é realmente alarmante. É certo que a questão transcende os limites do setor saúde, mas cabe alertar para a gravidade do problema, buscando, não só para esse, mas, para muitos outros, a adoção de medidas intersetoriais. As ações preventivas contra os acidentes, homicídios e suicídios, como causas de morte prematura, não guardam relação com a importância do fenômeno, em comparação com outros programas preventivos dirigidos contra problemas de magnitude e transcendência consideravelmente menor.

As doenças cardiovasculares e os neoplasmas, mesmo com a retirada dos óbitos maiores de 70 anos, continuaram aparecendo entre as principais causas de óbito. A incorporação na rotina da atenção primária de medidas de promoção da saúde pode, junto com o diagnóstico precoce e pronto tratamento, colaborar no seu controle.

Aparentemente, os resultados encontrados colocam a situação de mortalidade de Santa Catarina em um padrão de transição, onde aparecem como principais causas de óbito doenças típicas de populações desenvolvidas, como as crônico-degenerativas e as causas externas, alternando em importância com doenças características de localidades com baixo nível de saúde, como as infecciosas intestinais.

As infecções intestinais, por exemplo, passaram da $17^{\text {a }}$ para $12^{a}$ posição, tendo sido um dos grupos que mais "roubou" anos potenciais de vida de suas vítimas (55,2 APVP por óbito). Assim, o conjunto de ações dirigidas ao controle das doenças diarréicas deve ser implementado e o seu impacto, assim como o de outros programas específicos, em termos de redução da mortalidade, monitorado, através de análises temporais.

A lista CID-BR2, utilizada para a agregação das causas de óbito, mostrou ser mais apropriada à análise dos dados, na medida em que fornece uma visão mais voltada para a capacidade de atuação do setor saúde, mas, pode ainda ser melhorada, com destaque, por exemplo, da AIDS, que vem aumentando sua participação na mortalidade geral. Se esta causa fosse incluída na análise, como categoria discriminada, ocuparia a $10^{\mathrm{a}}$ posição na escala hierárquica da ordenação segundo os APVP, sendo responsável por 13.415 APVPs.

As causas mal definidas ainda representam $12,1 \%$ do total de óbitos em 
Santa Catarina e esse número precisa ser reduzido porque a definição desses óbitos poderia alterar o padrão de mortalidade encontrado. Além da questão da qualidade do preenchimento das declarações de óbito, esse percentual indica que o acesso aos serviços de saúde não está sendo garantido à população.

Considerando a simplicidade de cálculo do indicador APVP e a riqueza de informações por ele geradas, é possível que a metodologia empregada neste estudo possa ser incorporada ao planejamento e avaliação das ações de saúde, estendendo-se a outros grupos de causas de morte, contribuindo, assim, para uma melhor definição de prioridades e auxiliando no desenho das estratégias e táticas de intervenção requeridas.

$\mathrm{O}$ emprego de indicadores para a avaliação de causas de morte prematura está relacionado, de forma implícita, com o objetivo da saúde pública, que é a prevenção de danos à saúde; no caso da mortalidade, a prevenção se traduz em ações tendentes a postergar a morte, dado ser este um evento inevitável. Nesse sentido, a interpretação do indicador proposto está relacionada com a redução da quantidade de vida potencial que certas causas de óbito ocasionam e com a possibilidade de evitar a perda, mediante a prevenção dessas mortes.

\section{Bibliografia}

1. Werneck GL, Reichenheim ME. Anos potenciais de vida perdidos no Rio de Janeiro,1985. As mortes violentas em questão. Universidade do Estado do Rio de Janeiro, (série: Estudos em Saúde Coletiva) 1992; 4: 1-20.

2. Becker RA, Moreira MG, Costa JL. Anõs de vida potencial perdidos: Brasil, 1980. Boletin Epidemiológico OPS 1984; 5(5): 3-7.

3. E.U.A. Centers for Disease Control. Leads from the. Years of potencial life lost before age 65 - United States, 1988 and 1989. MMWR 1991; 40(4): 62-63, 69-71.

4. Costa ML. Anos potenciais de vida perdidos: munícipio de São Paulo década de 70 [Dissertação de Mestrado]. São Paulo: Faculdade de Saúde Pública da Universidade de São Paulo; 1987. 59 p.

5. Ortega-Cavasos N, Rio-Zolezzi A, Izazola-Licea JA, Lezana-Fernandez MA, Valdespino-Gomez JL. Años de vida potencial perdidos: su utilidad en analisis de la mortalidad en México. Salud Pública de México 1989; 31(5): 610-624.

6. BRASIL. Classificação Internacional de Doenças, Lesões e causas de óbitos: 9a revisão, 1975. São Paulo: Centro da OMS para Classificação de Doenças em Português; 1978. 815 p.

7. Romeder JM, McWhinnie JR. Años de vida potencial perdidos entre las edades de 1 y 70 años: un indicator de mortalidad prematura para la planificatión de la salud. In: Buck, C.(org) El Desafío de la Epidemiologia. Washington: OPAS; 1988.

8. Becker RA, Lima DD, Lima JTF, Costa Jr. ML. Investigação sobre perfis de saúde:Brasil, 1984. Brasília: Centro de Documentação do Ministério da Saúde, (Série C: estudos e projetos, 8); 1989. 63 p.

9. Souza M L, Laurenti R. Mortalidade Materna: conceitos e aspectos estatísticos. São Paulo: Centro da OMS para a Classificação de Doenças em Português. Núcleo de Estudos em População e Saúde. (Série Divulgação, 3); 1987.

10.Laurenti R, Jorge MHPM, Lebrão ML, Gotlieb SLD. Estatísticas de Saúde. São Paulo: Editora Pedagógica e Universitária Ltda; 1985. 